Article

\title{
Laboratory and Field Studies of $\operatorname{Poly}(2,5-b i s(N$-methyl- $N$-hexylamino)phenylene vinylene) (BAM-PPV): A Potential Wash Primer Replacement for Army Military Vehicles
}

\author{
Peter Zarras ${ }^{1, *}$, Christopher E. Miller ${ }^{2}$, Cindy Webber ${ }^{1}$, Nicole Anderson ${ }^{1}$ \\ and John D. Stenger-Smith ${ }^{1}$
}

1 Naval Air Warfare Center Weapons Division (NAWCWD), Polymer Science \& Engineering Branch (Code 4L4200D), 1900 N. Knox Road (Stop 6303), China Lake, CA 93555-6106, USA;

E-Mails: cynthia.webber@navy.mil (C.W.); nicole.anderson@navy.mil (N.A.); john.stenger-smith@navy.mil (J.D.S.-S.)

2 Army Research Laboratory, Coatings and Corrosion, Building 4600, ARSRD-ARL-WM-SG Aberdeen Proving Ground, MD 21005-5069, USA; E-Mail: christopher.e.miller44.civ@mail.mil

* Author to whom correspondence should be addressed; E-Mail: peter.zarras@navy.mil; Tel.: +1-760-939-1396; Fax: +1-760-939-1617.

Received: 13 June 2014; in revised form: 8 August 2014 / Accepted: 21 August 2014 /

Published: 15 September 2014

\begin{abstract}
In this study, an electroactive polymer (EAP), poly(2,5-bis $(N$-methyl- $N$ hexylamino)phenylene vinylene) (BAM-PPV), was tested as an alternative to current hexavalent chromium ( $\mathrm{Cr}(\mathrm{VI})$ )-based Army wash primers. BAM-PPV was tested in both laboratory and field studies to determine its adhesive and corrosion-inhibiting properties when applied to steel and aluminum alloys. The Army Research Laboratory (ARL) tests showed that BAM-PPV combined with an epoxy primer and the Army chemical agent-resistant coating (CARC) topcoat met Army performance requirements for military coatings. After successful laboratory testing, the BAM-PPV was then field tested for one year at the Aberdeen Test Center (ATC). This field testing showed that BAM-PPV incorporated into the Army military coating survived with no delamination of the coating and only minor corrosion on the chip sites.
\end{abstract}


Keywords: $\quad \operatorname{poly}(2,5$-bis( $N$-methyl- $N$-hexylamino)phenylene vinylene (BAM-PPV); wash primer; adhesion; corrosion-inhibiting; hexavalent chromium ( $\mathrm{Cr}(\mathrm{VI}))$; grit blasting; field studies

\section{Introduction}

The Army wash primer (DOD-P-15328D) that is currently used on Army military vehicles was developed during World War II. It is a two-component system consisting of a zinc chromate rust inhibiting pigment in a flexible adhering polymer solution activated by phosphoric acid just before use [1,2]. The Army wash primer is used as the pretreatment coating for surfaces, such as moist steel, aluminum, galvanized steel, brass and stainless steel [3]. The Army wash primer chemically alters the surface of these metals and consequently provides an excellent surface for receiving primers or topcoats. The phosphate treatment provides a non-metallic barrier against corrosion and ensures a roughened surface. This roughness provides more surface area for the adhesion of the polyvinyl butyral (pvb) resin when the Army wash primer cures. The reaction of the Army wash primer with the substrate surface produces a phosphate layer and a crosslinked resin containing organocomplexes that adheres strongly to the surface of the phosphate layer. The Army wash primer acts as a single-coat, self-stratifying, multi-layer coating, which consists of: (1) an unpigmented resin layer at the free surface; (2) a pvb-phosphoric acid-chromium layer; and (3) a phosphate layer at the metal surface (Figure 1) [4,5]. A solution of hexavalent chromium ( $\mathrm{Cr}(\mathrm{VI}))$ ions is then added to passivate the metal surface. The zinc chromate is basic and reacts with the phosphoric acid to form a mixture of chromium in both cationic and anionic forms. The $\mathrm{Cr}(\mathrm{VI})$ is available for passivating the phosphate surface, insuring a three-dimensional organic-metallic polymer coating. This coating is capable of inhibiting corrosion and promoting adhesion between the metal substrate and epoxy primer layer.

Figure 1. Schematic diagram of multi-layer Cr(VI)-based Army wash primer (DOD-P-15328D) coating on metal substrate.

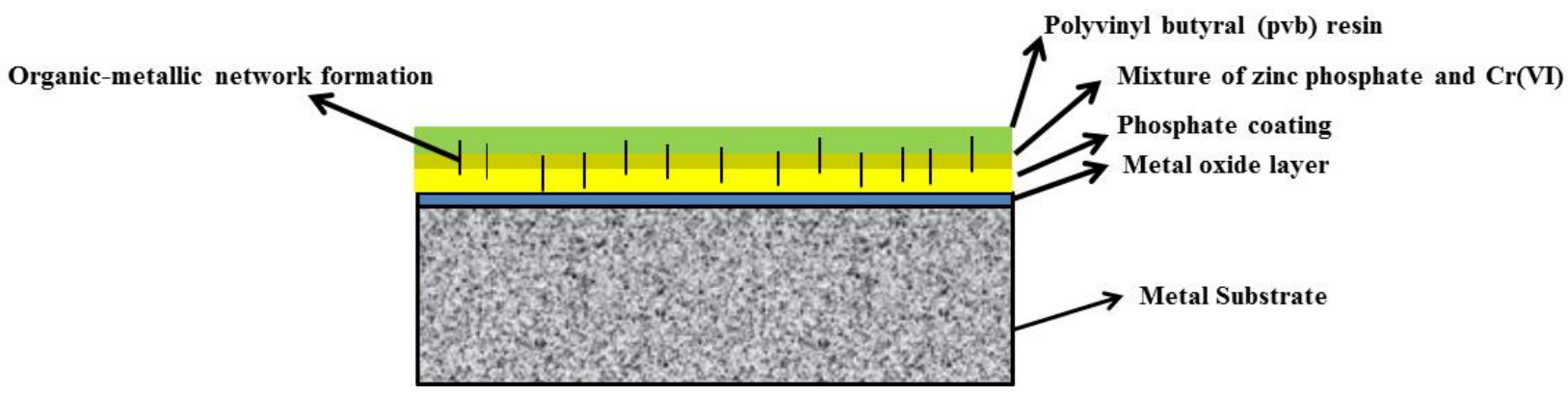

Next, the Army wash primer is coated with an epoxy primer, followed by the Army's chemical agent resistant coating (CARC) polyurethane topcoat (Figure 2).

$\mathrm{Cr}(\mathrm{VI})$ has been shown to inhibit corrosion through a release of unreacted and available $\mathrm{Cr}(\mathrm{VI})$ when exposed to a corrosive environment via "a self-healing mechanism" [6-9]. The storage and release of soluble $\mathrm{Cr}(\mathrm{VI})$ enables chromate conversion coatings (CCC's) and $\mathrm{Cr}(\mathrm{VI})$-epoxy primers to passivate 
defects and scratches $[10,11]$. Unfortunately, $\mathrm{Cr}(\mathrm{VI})$, which is used in Army wash primer coatings, has been identified as a toxic and carcinogenic material [12-15]. In order to meet new federal and state environmental regulations and to protect worker safety, alternative coating systems that reduce or eliminate $\mathrm{Cr}(\mathrm{VI})$ are urgently needed.

Figure 2. Schematic diagram of DOD Cr(VI)-based Army wash primer with military coating [epoxy primer and chemical agent resistant coating (CARC) topcoat] on a metal substrate.

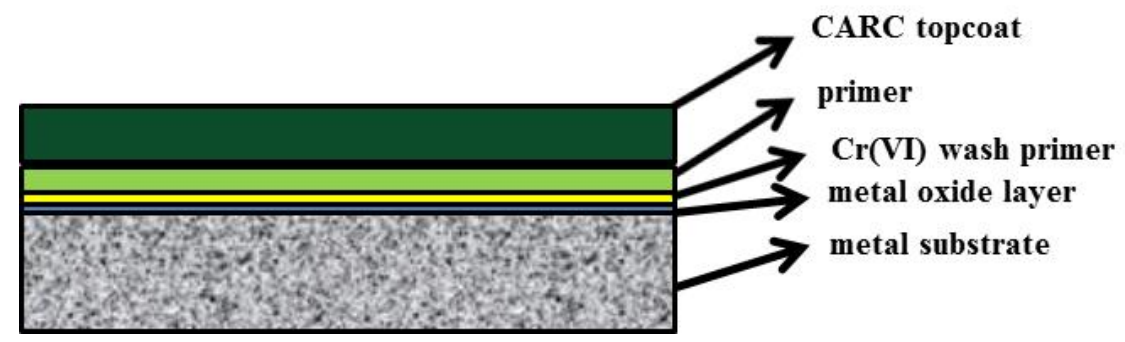

Electroactive polymers (EAPs) have been investigated at the laboratory scale and commercialized as viable corrosion-inhibiting coatings [16-20]. Polyaniline (PANI) is one of the most studied EAPs for corrosion inhibition. PANI-dispersions in an epoxy formulation under the trade name CORRPASSIVTM have been commercialized. This product has found widespread use in numerous countries throughout Europe and Asia. PANI-dispersions are used in diverse applications and in a variety of corrosive environments, such as waste water treatment plants, construction materials (bridges) and commercial steel structures. PANI has shown corrosion-inhibition via a passivation mechanism on steel substrates. PANI dispersions and PANI-containing lacquers were used to coat steel samples to provide primer layers of between 0.3 and $20 \mu \mathrm{m}$. These PANI dispersive layers were observed to shift the corrosion potential in the direction of the "noble region" [21].

There are several reports of EAPs used as replacements for the $\mathrm{Cr}(\mathrm{VI})$-based wash primer [22,23]. These studies focused on laboratory testing of the EAP via electrochemical and ASTM methods, which provided evidence for corrosion protection of the underlying metal. Poly(2,5-bis $(N$-methyl- $N$ hexylamino)phenylene vinylene) (BAM-PPV) has been studied and tested at the Naval Air Warfare Center Weapons Division (NAWCWD) for its corrosion-inhibiting properties. The mechanism of BAM-PPV's corrosion-inhibition was investigated via electrochemical methods. BAM-PPV coated onto AA 2024-T3 alloy provided corrosion inhibition via a surface passivation mechanism [24]. BAM-PPV was then field tested as a CCC replacement by researchers at the NAWCWD in cooperation with Wright-Patterson Air Force Base (WPAFB) (Figure 3). This EAP was coated on the rear cargo hatch door of the C-5 Galaxy aircraft. BAM-PPV was incorporated into an aerospace coating (non-Cr(VI) epoxy primer and polyurethane topcoat). It was then shown to survive a one-year field test without any evidence of delamination or corrosion. The BAM-PPV military coating was compared to a $\mathrm{Cr}(\mathrm{VI})$ aerospace coating (CCC, $\mathrm{Cr}(\mathrm{VI})$ epoxy primer and polyurethane topcoat) and had similar corrosion and adhesion performance during Air Force field testing [25].

Based on the successful results from the field tests performed by WPAFB, this study was undertaken to investigate BAM-PPV as a potential alternative to the $\mathrm{Cr}(\mathrm{VI})$-based Army wash primer. The NAWCWD in cooperation with the Army Research Laboratory (ARL) focused on laboratory testing, including accelerated weathering and adhesion tests. In addition to laboratory testing of BAM-PPV's 
adhesion and corrosion inhibiting properties, toxicology testing was performed on laboratory animals using BAM-PPV powder as the unknown material to determine its potential lethality in the workplace environment. BAM-PPV was tested for its toxicity and found to be a nontoxic, non-dermal irritant and is not a sensitizer [26]. Once these laboratory tests were completed showing that BAM-PPV is a potential $\mathrm{Cr}(\mathrm{VI})$-based Army wash primer alternative and is non-toxic, it was then field tested.

Figure 3. Structure of poly(2,5-bis( $N$-methyl- $N$-hexylamino)phenylene vinylene) (BAM-PPV).

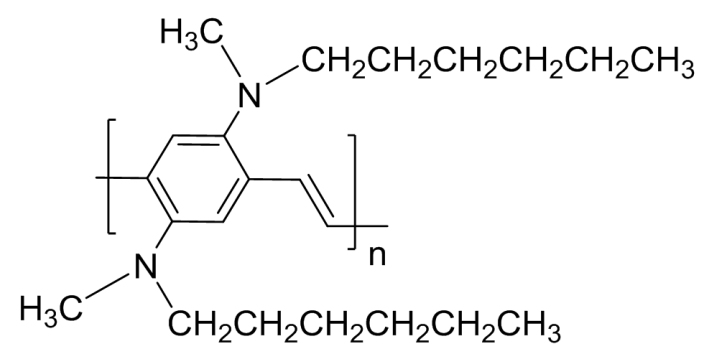

where $\mathrm{n}>1$

\section{Experimental Section}

\subsection{Materials}

The monomer, 2,5-bis(chloromethyl)-4-(hexamethylamino)-phenyl)hexamethylamine dihydrochloride, was prepared according to published work [27-29]. Acetonitrile, methanol, toluene, tetrahydrofuran (THF) and potassium $t$-butoxide $(\mathrm{K}-t$-OBu) were obtained from Aldrich Chemical Company and used without further purification. 4130 steel coupons and aluminum alloys (AA 6061-T6 and AA 5083-H116) were purchased from Q-Lab Corporation.

\subsection{Polymerization of 2,5-Bis(chloromethyl)-4-(hexamethylamino)-phenyl)hexamethylamine}

\section{Dihydrochloride}

The polymerization of the monomer, 2,5-bis(chloromethyl)-4-(hexamethylamino)-phenyl)hexamethylamine dihydrochloride, was carried out in a 5-L reactor with a mechanical stirrer. The reactor was placed inside a large stainless steel secondary container to allow cooling. Toluene (2 L) and THF (2 L) were added to the reactor. Dry ice was added to the secondary container containing acetonitrile to cool the reactor to $-45^{\circ} \mathrm{C}$. While the solvent was cooling, 100-150 g of monomer were added, and when the temperature reached $-45{ }^{\circ} \mathrm{C}, 8$ molar equivalents of $\mathrm{K}$ - $t$-OBu were added. The temperature was kept between $-45^{\circ} \mathrm{C}$ and $-55^{\circ} \mathrm{C}$ for $2 \mathrm{~h}$. After $2 \mathrm{~h}$, the solution was then allowed to warm to ambient temperature overnight. After $18 \mathrm{~h}$, the reaction mixture was found to be a very viscous orange, semi-gelatinous material. The polymer was precipitated by pouring this viscous orange material into methanol, filtered through a glass frit and dried under vacuum $(1.0 \mathrm{mmHg})$ at $100^{\circ} \mathrm{C}$ overnight.

After drying, the polymer was placed in a Soxhlet thimble and extracted with methanol to remove oligomers and potassium chloride $(\mathrm{KCl})$ salts. The extraction was followed by rinsing with methanol, filtering and drying to constant weight. The crude polymer was mechanically agitated with vigorous stirring using de-ionized water (DI water):methanol $(90: 10, \mathrm{~V} / \mathrm{V})$ as the extractant for one week to 
remove any remaining $\mathrm{KCl}$ salts. The suspension was filtered and the powder dried for one day under vacuum $\left(0.5 \mathrm{mmHg}, 25^{\circ} \mathrm{C}\right)$ to constant weight. BAM-PPV was obtained as an orange-yellow powder in 93\% yield. The BAM-PPV was characterized via ${ }^{1} \mathrm{H}$ NMR, ${ }^{13} \mathrm{C}$ NMR and FTIR spectroscopy for structure and elemental analysis for chemical composition. The data was consistent with previous reports on BAM-PPV properties, confirming the product [24,28,29].

\subsection{BAM-PPV Solution Preparation}

The BAM-PPV polymer was ground to a fine powder using a commercial coffee grinder. 4-Chlorobenzotrifluoride (Oxsol-100) (VOC-exempt) was used to dissolve the BAM-PPV powder. The BAM-PPV powder was added to the Oxsol-100 solvent with vigorous stirring. The BAM-PPV suspension was heated at $60{ }^{\circ} \mathrm{C}$ to dissolve any remaining BAM-PPV powder. After 3 days of mixing, a $\sim 1 \mathrm{wt} \%$ solution was obtained. The BAM-PPV solution was filtered through a Buchner funnel fitted with a coarse filter paper (Fisherbrand filter paper, porosity: coarse; diameter: $18.5 \mathrm{~cm}$ ) to remove trace amounts of impurities present in the solution. The filtrate was then ready for the next step (Section 2.4), which consisted of coating the metal substrates.

\subsection{BAM-PPV and DOD-P-15328D Wash Primer Coatings Application on Metal Substrates}

The BAM-PPV solutions were sprayed onto aluminum alloy (AA) substrates [(AA 6061-T6 $(3 \times 6 \times 0.032 ") ;$ AA $\left.5083-H 116\left(3 \times 6 \times 0.125^{\prime \prime}\right)\right]$ and high strength 4130 steel substrate $\left(3 \times 6 \times 0.25^{\prime \prime}\right)$ using an air brush technique. The BAM-PPV coating was applied to the as-received aluminum alloys. The as-received and grit-blasted 4130 steel substrate were coated with BAM-PPV solution via an air brush spray. The aluminum and steel alloys coated with BAM-PPV were dried under vacuum ( $1 \mathrm{mmHg}$, $60{ }^{\circ} \mathrm{C}$ ) for $12 \mathrm{~h}$, giving an orange-colored film. The dry film thickness was determined to be between 1.9 and $2.2 \mu \mathrm{m}$.

For the field demonstration, the AA 2024-T3 metal substrate on the Bradley vehicle headlight cover was used. This aluminum substrate part of the Army's inventory was grit blasted to remove all coatings from the metal surface. BAM-PPV was sprayed via high volume low pressure (HVLP) spray equipment directly onto the metal surface of the Bradley vehicle headlight cover. The BAM-PPV pretreatment coating was dried under ambient conditions to give a dry coating thickness of $>2.0 \mu \mathrm{m}$. The Army wash primer, DOD-P-15328D, was used as the control and was applied to metal substrates according to the manufacturer's instructions using HVLP coating methods to give a dry film thickness of between 0.3 and 0.5 mils.

\subsection{Primer(s) and Topcoat(s) Application to the BAM-PPV Pretreatment Coating}

The Army primer that was used to coat the BAM-PPV pretreatment coating was MIL-DTL-53022D. A description of the MIL-DTL-53022D primer is found in Table 1. This primer was applied using HVLP coating application methods. The coatings were mixed according to the manufacturer's instructions and applied using a DeVilbiss GTi HVLP Gun with a \#413 needle, \#100 cap size, a cap fluid pressure setting of 2 psi, a line pressure setting of 40 psi, a hose length of 30 feet and a hose diameter of $3 / 8$ ". Coatings were applied using a single cross coat to generate an overall dry film coating thickness of between 0.6 and 
0.9 mils. The MIL-DTL-53022D primer was applied onto both laboratory coupons and the Army Bradley vehicle headlight cover.

Table 1. Army primers and topcoats used for laboratory and field studies.

\begin{tabular}{ccl}
\hline Coating & Military Specification & \multicolumn{1}{c}{ Description } \\
\hline Primer & MIL-DTL-53022D & chromate and lead-free, solvent-borne, epoxy primer \\
\hline Topcoat & MIL-DTL-53039 & $\begin{array}{l}\text { chromate and lead-free, solvent-borne, single-component moisture } \\
\text { cure aliphatic polyurethane camouflage CARC coating }\end{array}$ \\
\hline Topcoat & MIL-DTL-64159 & $\begin{array}{l}\text { chromate and lead-free, water-borne, two-component polyurethane } \\
\text { CARC coating }\end{array}$ \\
\hline
\end{tabular}

The Army topcoats, MIL-DTL-53039 and MIL-DTL-64159, were mixed according to manufacturer instructions and applied using the above settings, but with two cross coats to generate an overall dry film coating thickness of approximately 1.2 mils. A description of the topcoats, MIL-DTL-53039 and MIL-DTL-64159 are found in Table 1. MIL-DTL-53039 and MIL-DTL-64159 were applied to laboratory coupons, and only MIL-DTL-64159 was applied onto the Army Bradley vehicle headlight cover. The primer and both topcoats were dried using standard drying conditions (ambient conditions $\sim 77^{\circ} \mathrm{F}$ and $50 \%$ RH for 14 days).

\subsection{Pull-Off Adhesion ASTM D 4541 (Pneumatic Adhesion Tensile Test Instrument) PATTI}

The pneumatic adhesion tensile test instrument (PATTI) pull-off test is designed to give specific information concerning both the inter-coat adhesion and the intra-coat cohesion of organic coating systems [30]. The pull-off adhesion testing of BAM-PPV coatings with primer and topcoats was conducted to assess the effects of the surface preparation at the substrate and the pretreatment. These tests were performed in accordance with ASTM D 4541. An Elcometer Model 108 Hydraulic Adhesion Test Equipment (HATE) was used for this procedure. In addition to being a more quantitative test method, pull-off adhesion is also less prone to human errors in testing, such as variations in pressure applied during scribing, as well as interpretation and perception of results. For the pull-off adhesion test, a loading fixture commonly referred to as a "dolly" was secured normal to the coating surface using an adhesive. The adhesive used was cyanoacrylate. After allowing the adhesive to cure for $24 \mathrm{~h}$ at $25^{\circ} \mathrm{C}$ in ambient conditions, the attached dolly was inserted into the test apparatus.

The load applied by the apparatus was gradually increased and monitored on the gauge until a plug of coating was detached. The failure value (in psi) was recorded, and the failure mode was characterized. For pull-off data to be valid, the specimen substrate must be of sufficient thickness to ensure that the coaxial load applied during the removal stage does not distort the substrate material and cause a bulging or "trampoline effect". When a thin specimen is used, the resultant bulge causes the coating to radially peel away outwards from the center instead of being uniformly pulled away in pure tension and, thus, results in significantly lower readings than for identically prepared specimens with greater substrate thickness. At 0.25 inches, all of the metallic panels evaluated in the test matrix had adequate thickness for valid pull-off test results. Measurements for each coating system and substrate were obtained by taking 16 measurements on each of the two panels. Any failure measurements due to coating separation between the topcoat surface and the cyanoacrylate adhesive were rejected. 


\subsection{Neutral Salt Spray (NSS) Exposure Testing}

Neutral salt spray (NSS) exposure testing was performed to evaluate the ability of the coating systems to withstand a $5 \mathrm{wt} \%$ sodium chloride solution, $\mathrm{pH}$-adjusted to a range of 6.5-7.2 [31]. This test was performed on pretreatment, primed and CARC topcoated systems on both steel and aluminum alloy substrates. NSS exposure testing was conducted, in accordance ASTM B 117, Standard Practice for Operating Salt Spray (Fog) Apparatus. All samples subjected to NSS exposure tests were photographed before and after testing to document the performance of the coating. There were three replicates per coating system. The guidance for sample evaluation was taken from MIL-PRF-23377, Performance Specification, Primer Coatings: Epoxy, High Solids. All coupons were primed, topcoated and then scribed with an X-scribe (full size). The 4130 steel coupons were then exposed to NSS for up to $432 \mathrm{~h}$. The AA 6061-T6 and 5083-H116 coupons were also exposed to NSS exposure testing for up to $2016 \mathrm{~h}$.

All samples were checked for blistering, loss of adhesion, undercutting, pitting and corrosion build-up in the scribe. The rating systems for pretreatment, primed and CARC topcoated samples exposed to NSS are given in Table 2. ASTM D 1654 Method A is used for the scribed regions and Method B for the non-scribed regions. Final images were taken upon completion of exposure. BIF stands for blisters in field and means that there was creep from scribe and blistering of the non-scribed regions. Furthermore, where there are two numbers in a rating for the scribed panel, the first number indicates the ASTM D 1654 rating of the scribe and the second is the rating for those areas away from the scribe.

Table 2. Performance rating for ASTM 1654 Methods A and B.

\begin{tabular}{ccc}
\hline Color Code & Rating & Blister Size \\
\hline green & $8-10$ (pass) & very small-none \\
yellow & $6-7$ (pass) & small \\
orange & $4-5$ (marginal) & medium \\
red & $1-3$ (failure) & delamination-large \\
\hline
\end{tabular}

\section{Results and Discussion}

\subsection{Adhesion Testing of BAM-PPV Military Coatings}

There are several modes of failure when a coating is removed from a substrate using axial tension [32-34]. These modes of failure include: adhesive debonding, cohesive debonding and mixed-mode debonding. Adhesive debonding is the force necessary to separate components of different substances (metal-coating), whereas cohesive debonding is the force necessary to separate components of the same substance (coating-coating) [35]. The results presented in Table 3 are only comparative; they do not provide information regarding whether a coating passes or fails this specific test.

The results of the PATTI adhesion tests (see Table 3) shows that BAM-PPV pretreatment with MIL-DTL-53022 primer and either CARC topcoat MIL-DTL-53039 or MIL-DTL-64159 provided acceptable adhesion. The adhesion results were acceptable for both as-received and grit-blasted 4130 steel coupons. The adhesion was slightly improved using the MIL-DTL-64159 CARC topcoat on grit-blasted 4130 steel coupons, but slightly lower adhesion was observed on grit-blasted BAM-PPV with the MIL-DTL-53039 topcoat. Grit-blasted steel coupons were used to mimic Army depot de-painting 
operations and to determine if there were any adhesion differences between as-received and grit-blasted surfaces. Overall, the data showed that the adhesion was acceptable for both as-received and grit-blasted steel surfaces.

Table 3. Adhesion performance of BAM-PPV with MIL-DTL-53022 and CARC topcoats on 4130 steel coupons.

\begin{tabular}{cccccc}
\hline Substrate 4130 Steel & Pretreatment & Primer & Topcoat & Mode of Failure & Average psi \\
\hline as-received & BAM-PPV & MIL-DTL-53022 & MIL-DTL-53039 & adhesive & 917 \\
grit blasted & BAM-PPV & MIL-DTL-53022 & MIL-DTL-53039 & adhesive & 866 \\
as-received & BAM-PPV & MIL-DTL-53022 & MIL-DTL-64159 & adhesive & 801 \\
grit blasted & BAM-PPV & MIL-DTL-53022 & MIL-DTL-64159 & adhesive & 848 \\
\hline
\end{tabular}

\subsection{NSS Results for BAM-PPV on As-Received and Grit-Blasted 4130 Steel Coupons}

NSS exposure testing was performed on grit-blasted steel surfaces to mimic Army depot de-painting and cleaning operations prior to re-application of Army military coatings. Steel coupons were coated with BAM-PPV pretreatment, MIL-DTL-53022 primer and topcoated with MIL-DTL-53039 or MIL-DTL-64159. The failure criterion was an ASTM D 1654 rating of three or less. The majority of the 4130 steel coupon surfaces that were grit-blasted prior to coating with the BAM-PPV pretreatment completed the $432 \mathrm{~h}$ of NSS exposure testing. Table 4 provides the results of NSS exposure testing on as-received and grit-blasted 4130 steel coupons coated with pretreatment(s) and MIL-DTL-53022 primer and CARC topcoats (MIL-DTL-53039 or MIL-DTL-64159).

Table 4. ASTM D 1654 ratings for as-received and grit-blasted 4130 steel coupons in the neutral salt spray (NSS) chamber. BIF, blisters in field.

\begin{tabular}{ccccccc}
\hline Substrate 4130 Steel & Pretreatment & Primer & Topcoat & Scribe & $\mathbf{1 2 4} \mathbf{h}$ & $\mathbf{4 3 2} \mathbf{~ h}$ \\
\hline as-received & DOD-P-15328D & MIL-DTL-53022 & MIL-DTL-64159 & No & 9 & 7 \\
as-received & DOD-P-15328D & MIL-DTL-53022 & MIL-DTL-64159 & Yes & 9 BIF 8 & 6 BIF 6 \\
as-received & BAM-PPV & MIL-DTL-53022 & MIL-DTL-53039 & No & 9 & 4 \\
as-received & BAM-PPV & MIL-DTL-53022 & MIL-DTL-53039 & Yes & 5 BIF 8 & 4 BIF 2 \\
grit blasted & DOD-P-15328D & MIL-DTL-53022 & MIL-DTL-64159 & No & 7 & 5 \\
grit blasted & DOD-P-15328D & MIL-DTL-53022 & MIL-DTL-64159 & Yes & 9 BIF 7 & 5 BIF 6 \\
grit blasted & BAM-PPV & MIL-DTL-53022 & MIL-DTL-64159 & No & 8 & 5 \\
grit blasted & BAM-PPV & MIL-DTL-53022 & MIL-DTL-64159 & Yes & 8 BIF 7 & 5 BIF 5 \\
\hline
\end{tabular}

The DOD-P-15328D Army wash primer military coating (epoxy primer and CARC topcoat) was exposed to $432 \mathrm{~h}$ of NSS exposure testing. At $124 \mathrm{~h}$ of NSS exposure testing, almost all of the DOD-P-15328D-coated steel coupons (as-received or grit-blasted) showed similar corrosion performance. There was corrosion deterioration of the DOD-P-15328D-coated steel coupons at $432 \mathrm{~h}$ of NSS exposure testing.

The BAM-PPV military coating system (epoxy primer and CARC topcoat) provided similar corrosion protection as compared to the control DOD-P-15328D Army military wash primer coating at $124 \mathrm{~h}$ of NSS exposure testing. Overall, the best performing BAM-PPV military coating was BAM-PPV with MIL-DTL-53022 epoxy primer and MIL-DTL-64159 topcoat. After $432 \mathrm{~h}$ of NSS exposure testing, 
whether scribed or non-scribed, there was no evidence of delamination of the coating system from the steel coupons.

Figure 4 shows an example of BAM-PPV on as-received and grit-blasted 4130 steel coupon coated with MIL-DTL-53022 primer and topcoated with MIL-DTL-53039 after $432 \mathrm{~h}$ of NSS exposure testing. Figure 5 shows an example of the control 4130 steel coupons coated with DOD-P-15328D (Army $\mathrm{Cr}(\mathrm{VI})$-based wash primer), MIL-DTL-53022 epoxy primer and topcoated with MIL-DTL-64159. The Army wash primer was coated onto both (a) as-received and (b) grit-blasted steel coupons. In all cases using either MIL-DTL-53039 or MIL-DTL-64159 topcoats for both the scribed and non-scribed coupons showed evidence of corrosion and blistering. Both the scribed and non-scribed 4130 steel coupons coated with the control and the BAM-PPV military coating showed similar corrosion performance after $432 \mathrm{~h}$ of NSS exposure testing.

Figure 4. BAM-PPV coated on (a) as-received and (b) grit-blasted 4130 steel coupons with MIL-DTL-53022 epoxy primer and MIL-DTL-53039 topcoat after $432 \mathrm{~h}$ of NSS exposure testing.

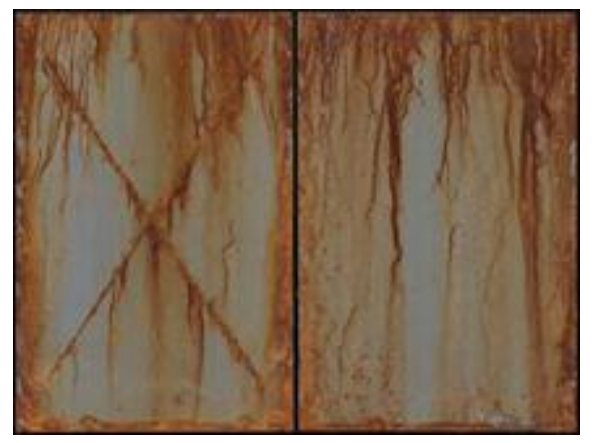

(a)

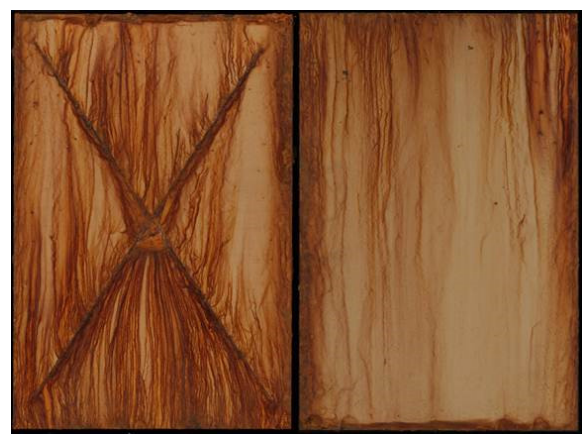

(b)

Figure 5. DOD-P-15328D coated on (a) as-received and (b) grit-blasted 4130 steel coupons with MIL-DTL-53022 primer and MIL-DTL-64159 topcoat after $432 \mathrm{~h}$ of NSS exposure.

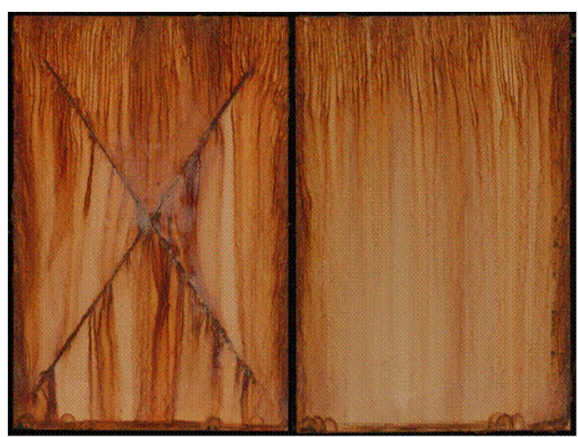

(a)

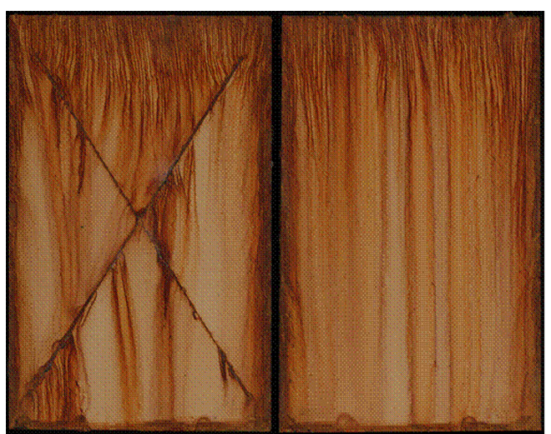

(b)

\subsection{NSS Results for BAM-PPV on As-Received Aluminum Coupons}

All of the aluminum coupons (AA 6061-T6 and AA 5083-H116) exposed to NSS were as-received without any surface finish. All of the scribed AA 6061-T6 and AA 5083-H116 coupons coated with BAM-PPV pretreatment followed by MIL-DTL-53022 epoxy primer and topcoated with CARC topcoat (MIL-DTL-53039 or MIL-DTL-64159) did not complete the $2016 \mathrm{~h}$ NSS exposure testing before 
extensive corrosion and delamination was evident in the scribed areas. This corrosion performance was consistent for either Army topcoat used during the NSS exposure testing. The data in Table 5 shows that all of the non-scribed panels independent of the topcoat used lasted through $2016 \mathrm{~h}$ for both the AA 6061-T6 and AA 5083-H116 coupons. There was no evidence of delamination for the non-scribed BAM-PPV Army coating at $2016 \mathrm{~h}$ of NSS exposure testing.

Table 5. ASTM D 1654 ratings for as-received AA 6061-T6 and AA 5083-H116 coupons in the NSS chamber.

\begin{tabular}{ccccccccc}
\hline Substrate & Pretreatment & Primer & Topcoat & Scribe & $\mathbf{1 6 8} \mathbf{h}$ & $\mathbf{5 0 4} \mathbf{h}$ & $\mathbf{1 2 4 8} \mathbf{h}$ & $\mathbf{2 0 1 6} \mathbf{h}$ \\
\hline AA 6061-T6 & BAM-PPV & MIL-DTL-53022 & MIL-DTL-53039 & No & 10 & 10 & 10 & 8 \\
AA 6061-T6 & BAM-PPV & MIL-DTL-53022 & MIL-DTL-53039 & Yes & 7 & 4 & $<1$ & $<1$ \\
AA 6061-T6 & BAM-PPV & MIL-DTL-53022 & MIL-DTL-64159 & No & 10 & 10 & 7 & 7 \\
AA 6061-T6 & BAM-PPV & MIL-DTL-53022 & MIL-DTL-64159 & Yes & 5 & 5 BIF 7 & 5 BIF 5 5 BIF 4 \\
AA 5083-H116 & BAM-PPV & MIL-DTL-53022 & MIL-DTL-53039 & No & 10 & 10 & 10 & 10 \\
AA 5083-H116 & BAM-PPV & MIL-DTL-53022 & MIL-DTL-53039 & Yes & 8 & 7 & 2 & 2 \\
AA 5083-H116 & BAM-PPV & MIL-DTL-53022 & MIL-DTL-64159 & No & 10 & 10 & 10 & 10 \\
AA 5083-H116 & BAM-PPV & MIL-DTL-53022 & MIL-DTL-64159 & Yes & 6 & 6 & 3 & 1 \\
\hline
\end{tabular}

\subsection{Field Test Results for BAM-PPV on Army Bradley Vehicle Aluminum Headlight Cover}

The aluminum headlight cover (AA 2024-T3) on the Bradley vehicle was chosen for the Army field testing due to the BAM-PPV military coating showing acceptable laboratory performance results in NSS exposure testing and adhesion studies. The reasons for selecting the headlight cover of the Bradley vehicle are as follows: (1) the Bradley vehicle is an ideal Army platform for assessing the performance of the BAM-PPV coating; and (2) the headlight cover is constructed of an aluminum alloy that provides the EAP a fair approximation of Army inventory.

The location of this vehicle at the Aberdeen Test Center (ATC) provided evaluators with several critical advantages over other locations. These critical advantages included: (1) the vehicle was assigned to the nearby test track, so it received a more aggressive exposure than would be expected from the typical environment of central Maryland; (2) the test track is used to test Army military coatings (wash primer, epoxy primer and CARC topcoat) in an accelerated environment that approximates the GM 9540 cyclic accelerated corrosion test; (3) ATC proximity to the Chesapeake Bay provides raised night time humidity and ameliorates temperature extremes; and (4) the ATC is only 1.5 miles from the personnel who would perform the periodic evaluations.

The Bradley vehicle headlight cover was grit blasted prior to coating with BAM-PPV to remove any Army coatings present on the metal surface. This was done to mimic the current de-painting operations at Army depots. BAM-PPV was sprayed onto the substrate using HVLP spray equipment, coated with MIL-DTL-53022 and topcoated with MIL-DTL-64159 (Figure 6). The vehicle was field tested at the ARL outdoor weathering test track and exposed to rain, snow, sleet, sun, wind, coastal moisture and humidity. Visual inspections for corrosion, adhesion, peeling and blistering were performed every three months. After one year of field testing, no significant corrosion, no blistering near edges and no undercutting of the coating adjacent to chip sites was observed. The chip sites that were present on the headlight cover were a result of wear during the one-year field test. This is considered acceptable 
performance for ARL field testing. There was slight corrosion present at chip sites where all coatings were removed (epoxy primer and CARC topcoat), including BAM-PPV (Figure 7). When the test method ASTM D 1654 Evaluation of Painted Specimens Subjected to Corrosive Environments there was limited corrosion damage after 12 months to areas where all coatings were removed, including BAM-PPV.

Figure 6. Coating procedure employed for de-painting and re-painting using BAM-PPV as the wash primer alternative coating followed by epoxy primer and the CARC topcoat (a) grit-blasted headlight cover; (b) the headlight cover coated with BAM-PPV; and (c) the headlight cover coated with MIL-DTL-53022 and MIL-DTL-64159.

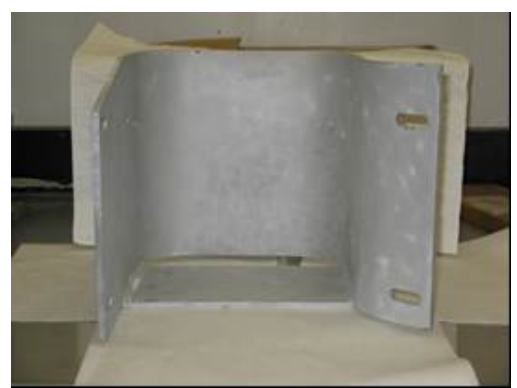

(a)

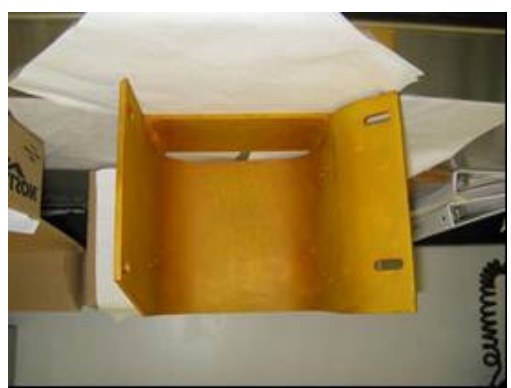

(b)

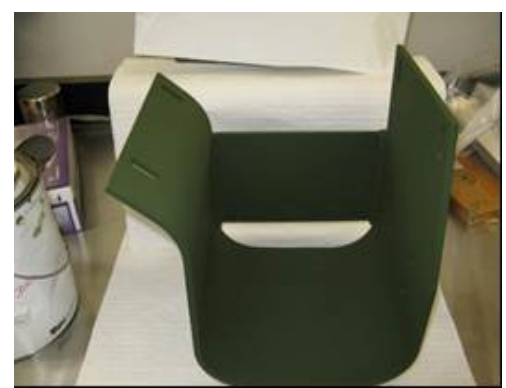

(c)

Figure 7. Wear damage after one-year of field testing the headlight cover: (a) wear damage front view; and (b) wear damage backside view.

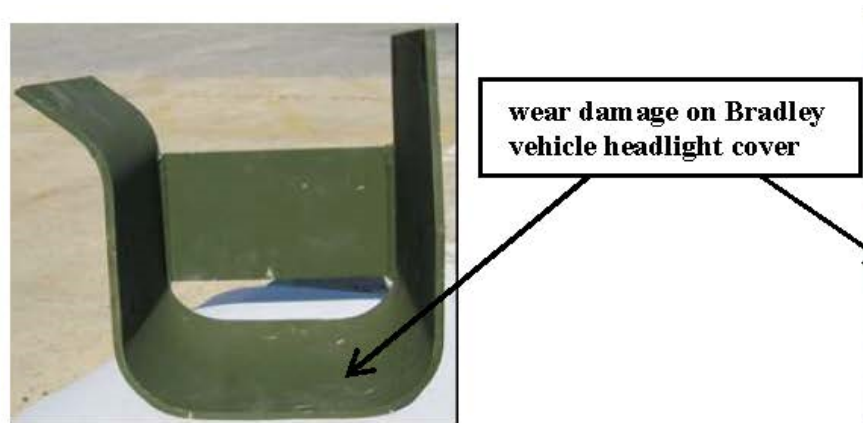

(a)

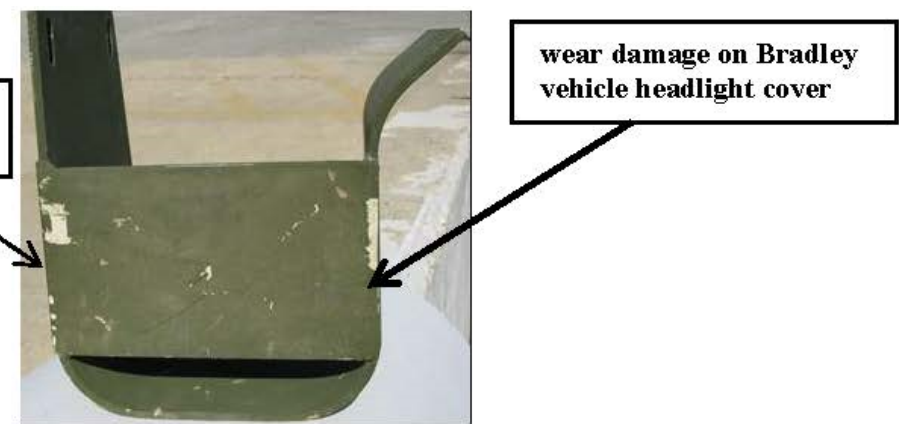

(b)

\section{Conclusions}

Several conclusions can be made regarding the laboratory and field testing studies incorporating BAM-PPV as a Cr(VI)-based wash primer replacement with full military coatings (epoxy primer and CARC topcoat):

(a) BAM-PPV showed slightly improved adhesion on grit-blasted 4130 steel surfaces as compared to as-received;

(b) BAM-PPV and DOD-P-15328D showed similar corrosion performance in NSS exposure testing;

(c) Results from the ARL field testing showed that BAM-PPV incorporated into Army military coating (epoxy primer and CARC topcoat) provided acceptable field performance; and

(d) BAM-PPV could be a potential alternative to $\mathrm{Cr}(\mathrm{VI})$-based wash primer on AA 2024-T3 substrates for the Army Bradley vehicle. 


\section{Acknowledgments}

The financial support of the Department of Defense (DOD) Environmental Security Technology and Certification Program (ESTCP), under the direction of Jeffrey Marqusee and Bruce D. Sartwell, Weapons Systems and Platforms Program Manager, is gratefully acknowledged.

\section{Author Contributions}

Peter Zarras, Cindy Webber, Nicole Anderson and John D. Stenger-Smith were responsible for synthesis, polymerization and coating BAM-PPV onto the as-received aluminum and steel substrates. Christopher E. Miller was responsible for coating BAM-PPV onto grit-blasted coupons and coating with primer and CARC topcoat. Christopher E. Miller was responsible for laboratory and field evaluation studies of BAM-PPV and Army wash primer coating controls.

\section{Conflicts of Interest}

The authors declare no conflict of interest.

\section{References}

1. Primer (Wash) Pretreatment (Formula No. 117 for Metals) DOD-P-15328D, Federal Specifications; Department of Defense: Washington, DC, USA, 2001.

2. Smith, P.; Chesonis, K.; Escarsega, J. Demonstration and Validation of a Replacement Alternative to the Chromate Wash Primer DOD-P-15328D, ARL-TR-3756; Army Research Laboratory: Adelphi, MD, USA, 2006; pp. 1-18.

3. Daley, R.R.; Hodges, S.A. Corrosion inhibitor for self-etching wash primers. Polym. Paint Colour J. 2010, 200, 18-20, 22, 24.

4. Chesonis, K.S.; Miller, C.E. VOC Compliant Wash Primer, ARL-MR-190; Army Research Laboratory: Adelphi, MD, USA, 1994.

5. Smith, P.; Chesonis, K.; Escarsega, J. Replacement Alternatives to the Chromate Wash Primer DOD-P-15328D, ARL-TR-3220; Army Research Laboratory: Adelphi, MD, USA, 2004.

6. Kendig, M.; Jeanjaquet, S.; Addison, R.; Waldrop, J. Role of hexavalent chromium in the inhibition of corrosion of aluminum alloys. Surf. Coat. Technol. 2001, 140, 58-66.

7. Illevbare, G.O.; Scully, J.R.; Yuan, J.; Kelly, R.G. Inhibition of pitting corrosion on aluminum alloy 2024-T3: Effect of soluble chromate additions vs. chromate conversion coating. Corrosion 2000, 56, 227-242.

8. Kendig, M.W.; Davenport, A.J.; Isaacs, H.S. The mechanism of corrosion inhibition by chromate conversion coatings from X-ray absorption near edge spectroscopy (XANES). Corros. Sci. 1993, 34, 41-49.

9. Chidambaram, D.; Halada, G.P.; Clayton, C.R. Spectroscopic elucidation of the repassivation of active sites on aluminum by chromate conversion coating. Electrochem. Solid State Lett. 2004, 7, B31-B33. 
10. Xia, L.; Akiyama, E.; Frankel, G.; McCreery, R. Storage and release of soluble hexavalent chromium from chromate conversion coatings equilibrium aspects of CrVI concentration. J. Electrochem. Soc. 2000, 147, 2256-2262.

11. Ramsey, J.D.; Xia, L.; Kendig, M.W.; McCreery, R.L. Raman spectroscopic analysis of the speciation of dilute chromate solutions. Corros. Sci. 2001, 43, 1557-1172.

12. Wise, S.S.; Wise, J.P. Chromium and genomic stability. Mutat. Res. Fundam. Mol. Mech. Mutagen. 2012, 733, 78-82.

13. Nickens, K.P.; Patierno, S.R.; Ceryak, S. Chromium genotoxicity: A double-edged sword. Chem. Biol. Interact. 2010, 188, 276-288.

14. Katz, S.A.; Ballantyne, B.; Salem, H. The inhalation toxicity of chromium compounds. In Inhalation Toxicity, 2nd ed.; Salem, H., Katz, S.A., Eds.; CRC Press: Boca Raton, FL, USA, 2006; pp. 543-564.

15. Sedman, R.M.; Beaumont, J.; McDonald, T.A.; Reynolds, S.; Krowech, G.; Howa, R. Review of the evidence regarding the carcinogenicity of hexavalent chromium in drinking water. J. Environ. Sci. Health Part C Environ. Carcinogen. Ecotoxicol. Rev. 2006, 24, 155-182.

16. Mengoli, G.; Munari, M.T.; Bianco, P.; Musiana, M.M. Anodic synthesis of polyaniline coatings onto iron sheets. J. Appl. Polym. Sci. 1981, 26, 4247-4257.

17. DeBerry, D.W. Modification of the electrochemical and corrosion behavior of stainless steels with an electroactive coating. J. Electrochem. Soc. 1985, 132, 1022-1026.

18. Ahmad, N.; MacDiarmid, A.G. Inhibition of corrosion of steels with the exploitation of conducting polymers. Synth. Met. 1996, 78, 103-110.

19. Yan, M.C.; Tallman, D.E.; Rasmussen, S.C.; Bierwagen, G.P. Corrosion control coatings for aluminum alloys based on neutral and n-doped conjugated polymers. J. Electrochem. Soc. 2009, 156, C360-C366.

20. Cecchetto, L.; Delabouglise, D.; Petit, J.-P. On the mechanism of the anodic protection of aluminum alloy AA5182 by emeraldine base coatings evidences of a galvanic coupling. Electrochim. Acta 2007, 52, 3485-3492.

21. Wessling, B. From conductive polymers to organic metals. Chem. Innov. 2001, 31, 35-40.

22. Pan, T. Intrinsically conducting polymer-based heavy-duty and environmentally friendly coating system for corrosion protection of structural steels. Spectrosc. Lett. 2013, 46, 268-276.

23. Sathiyanarayanan, S.; Syed, A.S.; Venkatachari, G. Corrosion protection of galvanized iron by polyaniline containing wash primer coating. Prog. Org. Coat. 2009, 65, 152-157.

24. Zarras, P.; He, J.; Tallman, D.E.; Anderson, N.; Guenthner, A.; Webber, C.; Stenger-Smith, J.D.; Pentony, J.M.; Hawkins, S.; Baldwin, L. Electroactive Polymer Coatings as Replacements for Chromate Conversion Coatings. In Smart Coatings, ACS Symposium Series 957; Provder, A., Baghdachi, J., Eds.; American Chemical Society: Washington, DC, USA, 2007; pp. 135-152.

25. Zarras, P.; Anderson, N.; Webber, C.; Stenger-Smith, J.D.; Spicer, M.; Buhrmaster, D. Electroactive materials as smart corrosion-inhibiting coatings for the replacement of hexavalent chromium. CoatingsTech 2011, 8, 40-44.

26. Zarras, P.; Stenger-Smith, J.D. Electroactive polymer (EAP) coatings for corrosion protection of metals. In Handbook of Smart Coatings for Materials Protection; Makhlouf, A.S.H., Ed.; Woodhead Publishing: Cambridge, UK, 2014; pp. 328-369. 
27. Stenger-Smith, J.D.; Anderson, N.; Webber, C.; Zarras, P. Poly(2,5-bis( $N$-methyl- $N$-hexylamino) phenylene vinylene) as a replacement for chromate conversion coatings. ACS Polym. Prepr. 2004, $45,150-151$.

28. Anderson, N.; Irvin, D.J.; Webber, C.; Stenger-Smith, J.D.; Zarras, P. Scale-up and corrosion inhibition of poly(bis(dialkylamino)phenylene vinylenes). ACS PMSE Prepr. 2002, 86, 6-7.

29. Irvin, D.J.; Anderson, N.; Webber, C.; Fallis, S.; Zarras, P. New Synthetic Routes to poly(bis(dialkylamino)phenylene vinylenes). ACS PMSE Prepr. 2002, 86, 61-62.

30. ASTM D4541 Standard Test Method for Pull-Off Strength of Coatings Using Portable Adhesion Testers; ASTM International: West Conshohocken, PA, USA, 2007.

31. ASTM B117 Standard Practice for Operating Salt Spray (Fog) Apparatus; ASTM International: West Conshohocken, PA, USA, 2007.

32. Mendels, D.A. Adhesion of multilayered coatings by low load scratch test. Tribol. Mater. Surf. Interfaces 2008, 2, 232-244.

33. Li, H.Z.; Jia, Y.; Luan, S.; Xiang, W.; Qian, H.; Charles, C.; Mamtimin, G.; Han, Y.; An, L. Influence of inter-fiberspacing and interfacial adhesion on failure of multi-fiber model composites: Experiment and numerical analysis. Polym. Compos. 2008, 29, 964-971.

34. Buchheit, R.G. Corrosion resistant coatings and paints. In Handbook of Environmental Degradation of Materials; Kutz, M., Ed.; William Andrew Publishing: Norwick, NY, USA, 2005; pp. 367-385.

35. Packman, D.E. Adhesion-Fundamental and Practical. In Handbook of Adhesion; Packman, D.E., Ed.; John Wiley and Sons: West Sussex, UK, 2005; pp. 17-21.

(C) 2014 by the authors; licensee MDPI, Basel, Switzerland. This article is an open access article distributed under the terms and conditions of the Creative Commons Attribution license (http://creativecommons.org/licenses/by/3.0/). 